\title{
Panel calls for fair deal for US postdocs
}

[WASHINGTON] Postdoctoral fellows at US universities are treated with "an unacceptable degree of variability and instability", according to a scathing report drawn up by the research universities themselves.

A panel of the American Association of Universities (AAU), which has been studying the problem for three years, recommends far more extensive oversight of postdoctoral education by the universities.

It calls for more reliable provision of healthcare insurance and other benefits for postdocs, and for strict time-limits that will stop people from languishing indefinitely in postdoc positions. The report also suggests that all postdocs should receive a "statement of goals, policies and responsibilities applicable to postdoctoral education" with their appointment letter.

The panel, chaired by Steven Sample, president of the University of Southern California in Los Angeles, points out that the postdoc has evolved from being an option to becoming an integral part of the training for university faculty positions.

"It is almost inconceivable today that someone would get a tenure-track post in the life sciences in a top university without having done a postdoc," says Sample.
But the universities - including the 50 AAU members who employ the overwhelming majority of 35,000 postdocs who work in the United States, according to the report have no policy for postdocs and exercise no oversight over their employment.

"Most institutions make little or no attempt to control the number or the quality of postdoctoral appointees on campus," the report says. "It is common for institutions either to have no time limits on postdoctoral appointments, or regularly to ignore or waive established limits."

The AAU report also acknowledges "the widely held perception that the postdoctoral appointment is being used as an employment holding pattern". Privately, university officials concede that postdocs are often seen by faculty as a cheap source of laboratory assistance, without adequate attention being paid to their own education or to their career-development needs.

And although institutions claim to give postdocs full employee benefits, postdocs surveyed by the AAU cited benefits as one of their main areas of concern. The report calls for all postdocs to gain access to comprehensive health care for themselves and their families. It isn't known how many postdocs cur- rently lack this, according to John Vaughn, executive vice-president of the AAU.

The report finds that, of the individuals who complete postdoc appointments, a quarter move on to another postdoc post, a quarter get a tenure-track faculty position, and one-tenth get a non-tenure-track faculty post. The others leave the academic world.

It recommends that initial postdoc appointments should last no longer than two or three years, and that the total time spent in postdoctoral positions should not exceed six years. "I think it is perfectly healthy to say to people that there is a time limit on postdocs," says Sample, adding that postdocs have to be "realistic" about the kind of job they will accept afterwards.

Neither Sample nor Vaughn could name an institution that has a statement of the goals of postdoctoral education of the type that the report suggests should be handed to postdocs with their appointment letter.

The AAU, which represents 50 leading research universities in both the public and private sectors, was founded in 1900 to coordinate the award of $\mathrm{PhDs}$ between universities. According to Sample, PhD education then was every bit as chaotic as postdoctoral education is today.

Colin Macilwain

\section{Computers hope to score at the football world cup for robots}

[PARIS] Scientists determined not to be left on the sidelines as France hosts football's four-yearly world cup next month are organizing a parallel event in Paris, the annual Robot Football World Cup.

More than 60 teams of robots from major research centres worldwide will take part. The event will be the largest gathering of autonomous robots ever, and will test the prowess of the participating countries in robotics and artificial intelligence.

The matches are open to robots between 4.5 and $50 \mathrm{~cm}$ high, and each will last 20 minutes, with the largest robots playing five-a-side on a pitch the area of 20 tabletennis tables. The robots must play as a team autonomously; human intervention is allowed only in cases of "serious fouls or very abnormal behaviour", such as attacking the goalposts.

Robot teams will be in permanent contact with their computer coach, however, which will analyse action on the pitch and send split-second instructions on tactics to the players.

The public competition is being organized at the Cité des Sciences et de l'Industrie in Paris from 30 June to 8 July. It is sponsored by RoboCup, a Swiss-based non-profit international association set up by researchers in artificial intelligence, and

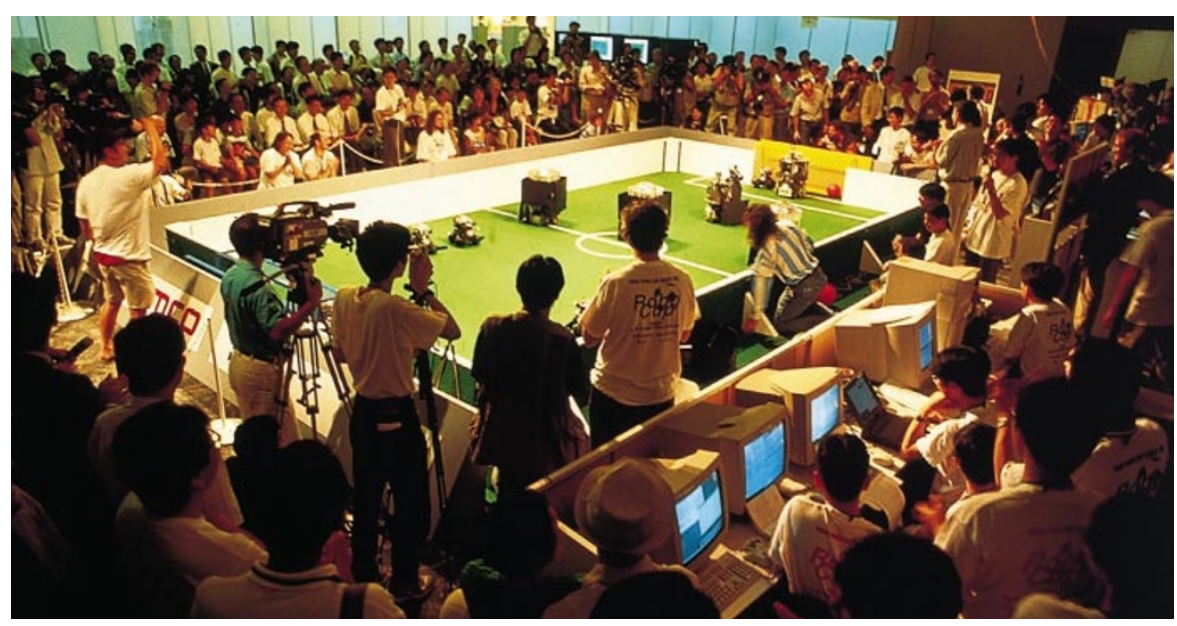

Computer game: robots test their artificial intelligence on the pitch in last year's world cup in Japan.

FIRA, a Korean-based organization that promotes work on cooperative autonomous robot systems.

The same venue will simultaneously host the 1998 International Conference on Multi-Agent Systems, the annual jamboree of artificial intelligence researchers.

The organizers say football poses a challenging task to robotic systems, as it tests their ability "to search, through real experimentation, the conditions for the emergence of collective intelligence".
Such research will have applications in developing autonomous, cooperative robots for planetary exploration, military operations and domestic tasks, for example.

Leaving aside advanced cooperative algorithms, the ability of teams to 'dribble' - a difficult task for robots - may well be a key factor in determining the outcome of the competition itself. Winning, as in the real game, ultimately depends not on elegant play but on being able to put the ball in the back of the net.

Declan Butler 